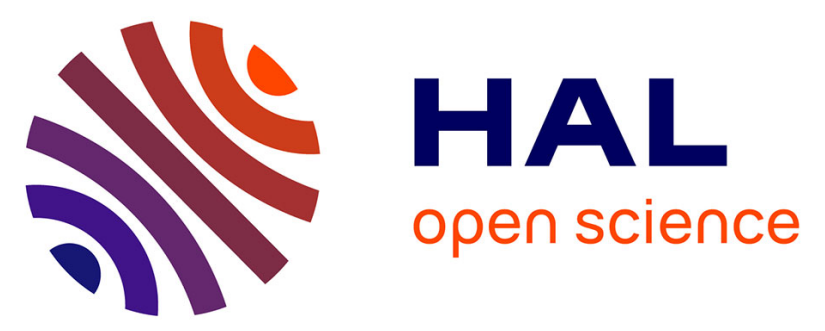

\title{
Modeling and Control of algae detachment in regulated canal networks
}

Ophélie Fovet, X. Litrico, Gilles Belaud

\section{To cite this version:}

Ophélie Fovet, X. Litrico, Gilles Belaud. Modeling and Control of algae detachment in regulated canal networks. IEEE International Conference on Control Applications, Sep 2010, Yokohama, Japan. 6 p. hal-00572225

\section{HAL Id: hal-00572225 \\ https://hal.science/hal-00572225}

Submitted on 1 Mar 2011

HAL is a multi-disciplinary open access archive for the deposit and dissemination of scientific research documents, whether they are published or not. The documents may come from teaching and research institutions in France or abroad, or from public or private research centers.
L'archive ouverte pluridisciplinaire HAL, est destinée au dépôt et à la diffusion de documents scientifiques de niveau recherche, publiés ou non, émanant des établissements d'enseignement et de recherche français ou étrangers, des laboratoires publics ou privés. 


\title{
Modeling and control of algae detachment in regulated canal networks
}

\author{
Ophelie Fovet, Xavier Litrico and Gilles Belaud
}

\begin{abstract}
Algae development in open-channel networks induce major disturbances because of clogging issues on hydraulic devices (pipes, weirs, filters,...). An original strategy to manage these algae developments consists in flushing the fixed algae. The flush is carried out by increasing the hydraulic shear conditions using the hydraulic structures of the canal network. In response to the shear stress increase, a part of the fixed algae is detached, then re-suspended into the water column, and finally transported into the canal network. This leads to a peak of turbidity. The present work aims at providing a design method for these flushes, based on a simplified detachment model. The efficiency of a flush will depend on its amplitude and duration. The design objective consists in maximizing the algae detachment using as little water as possible, and without overcoming a maximal turbidity level. We have developed a physical model to assess the impact of a flush on fixed and drift algae dynamics. We propose in this article a simplification of this model using linearization around a reference steady state regime. The linear simplified model can be used for automatic control design. The model parameters are identified on a real network: the branch of Marseilles North, part of the Canal de Provence, located in Southern France. The calibration is based on continuous monitoring of a quality parameter: the water turbidity. The calibrated model is then used to design the upstream discharge flush as an open-loop controller. Finally, flushes designed using the open-loop are tested on the simulation model, showing the interest of the method.
\end{abstract}

\section{INTRODUCTION}

Algae development on open-channel networks induce major disturbances such as clogging issues on hydraulic devices (pipes, weirs, filters...) and possible water quality depreciation. Current management strategies of the algae development consist in using chemicals or removing mechanically the fixed vegetation. Algaecides also depreciate the water quality and their use is not possible in canals that supply drinking water plants. Mechanical operations are costly and time-consuming and should be avoided too. Therefore, there is a need for new strategies of algae development which are consistent with the water resource preservation (in quantity and quality). The strategy studied in this article consists in regular flushes, causing an increase of the local shear stress conditions and a detachment of algae. Carrying out a flush every 2 to 3 weeks maintains an acceptable volume of biomass in the canal. The shear stress increase is obtained by releasing a volume of water at the canal head during a few hours, so that the mean bottom shear stress is increased

This work was supported by the French National Agency for Research O. Fovet, X Litrico and G. Belaud are with UMR G-EAU, Cemagref/Institut de recherche pour le Développement/ Montpellier SupAgro, 361 rue J-F. Breton, BP 5095, 34196 Montpellier cedex 05, France ophelie.fovet@cemagref.fr, xavier.litricolcemagref.fr,

belaudesupagro.inra.fr along the canal. It induces a detachment of fixed biomass which is then re-suspended into the water column. Two algal compartments are identified: the fixed one called benthic compartment, and the drift one composed of phytoplankton and detached algae. The higher the flush amplitude and duration, the higher their efficiency. However, turbidity increase must be limited in order to avoid clogging issues, and the added volumes of water must be limited in order to save the resource and to minimize the perturbations on the network. This management problem can be viewed as an optimization problem, consisting in achieving an objective of detached biomass with a minimum released volume of water, under constraints of turbidity and conveyance capacity.

Different optimal control strategies have been developed for river canal network management [12], [9], [13], [5], [8], based on hydraulic performance criteria. Their implementation in the field has been made possible by the development of sensors and SCADA systems [11], leading to more hydraulically efficient control strategies. Taking account of water quality objectives is more challenging, and to the best of our knowledge, little research work have been has been published in this domain [16]. Our objective is therefore to show how flow transfer and biomass detachment processes may be combined in an optimal open-loop control strategy, taking account of water quality constraints.

This paper builds on a 1D model recently developed to account for the impact of flushes on fixed and drift algae dynamics on real networks [3]. We first present this model which represents the algae detachment and transport in response to a flush. Then, we derive a simplified model obtained from the linearization of the complete model. The simplified model parameters are identified on a real network: the branch of Marseilles North, on the Canal de Provence (Southern France). The calibration is based on the continuous monitoring of a quality parameter: the water turbidity. The calibrated model is then used to design flushes as an open-loop controller, so that detached algae and maximum turbidity peak satisfy a set of constraints. Finally, the designed flushes are simulated with the complete model, which provides a first evaluation of the flush design methodology.

\section{A LINEAR MODEL OF FLUSHING-FLOWS IN OPEN-CHANNELS FOR ALGAE MANAGEMENT}

The benthic communities populations vary a lot in space and in time with many local scale interactions into the community. Consequently, the behavior of benthic colonies is very complex and depends on the biological stage (colonization, succession) [14]. A model has been proposed [3] to 
simulate flushes effects on the fixed algae in canals. It considers a global benthic population and no species distinction. The hydraulic behavior of the canal is modeled using the one dimensional Saint Venant equations as it is usually done for unsteady-flow simulation models in open channel [2]. This global approach is appropriate for a model dedicated to management. It simulates the detachment and the turbidity dynamics during a flush in each computation section of the canal. This model can be used to test different flow release scenarios. We propose in this article a simplification of this model using linearization around a reference steady state regime. This simplified model can then be used to design flushes as an open-loop controller [7], in order to satisfy operational constraints such as a maximum turbidity level. In this section, we first present the original model, then the simplified linear model.

\section{A. Physical model of algae dynamics in response to a hydraulic flush}

The system is represented in one dimension using the Saint Venant equations dealing with mass and momentum conservation:

$$
\begin{gathered}
\frac{\partial A}{\partial t}+\frac{\partial Q}{\partial x}=q \\
\frac{\partial Q}{\partial t}+\frac{\partial\left(\beta Q^{2} / A\right)}{\partial x}+g A \frac{\partial h}{\partial x}+g A\left(S_{f}-S_{b}\right)-\varepsilon q \frac{Q}{A}=0
\end{gathered}
$$

with $x$ the abscissa $(\mathrm{m}), t$ the time (s), $A$ the wetted area $\left(\mathrm{m}^{2}\right), Q$ the mean discharge $\left(\mathrm{m}^{3} \mathrm{~s}^{-1}\right), \beta$ the momentum coefficient, $g$ the gravitational acceleration $\left(\mathrm{m} \mathrm{s}^{-2}\right), h$ the water level (m), $S_{f}$ the friction slope, $S_{b}$ the bed slope, $q$ the lateral discharge inflow per unit of length $\left(\mathrm{m}^{3} \mathrm{~s}^{-1} \mathrm{~m}^{-1}\right)$, and $\varepsilon$ is equal to 0 if $q>0$ and to 1 if $q<0 . A, Q, h, S_{f}$, $S_{b}$ and $q$ depend on $x$ and $t$.

Solving these equations requires two boundary conditions and an initial condition. We used a model developed by the Cemagref [1] for the unsteady flow Simulation in Irrigation Canals (SIC). The boundary conditions are the hydrographs at the upstream end and at the lateral offtakes, and discharge hydrograph at the downstream end given by a function of the water level at these points. The initial condition is given by the water surface profile and discharge in each section at $t=$ 0 . Hydraulic singularities like cross structures are modeled using the continuity equation and a discharge equation. The equations are linearized and discretized using the Preissmann numerical scheme. With a computation time step around 510 minutes and a space step between 100 and $200 \mathrm{~m}$ the model is appropriate to simulate the flushes conducted on open-channels [3].

The processes involved in algae detachment are similar to erosion phenomena. The detachment is due to the hydraulic shear stress increase. We proposed a formulation for the algae detachment rate appropriate to describe the flush impact on the fixed algae in hard-surfaced open-channel [4]. This detachment rate is assumed to be proportional to the bottom average shear stress increase relatively to its critical value. It is also proportional to the stock of fixed biomass:

$$
\begin{gathered}
\rho_{d e t}=\frac{1}{a}\left(\frac{\tau_{0}-\tau_{0, c r}}{\tau_{0, c r}}-s\right)^{\xi} B \quad \text { if } \quad \frac{\tau_{0}-\tau_{0, c r}}{\tau_{0, c r}} \geq s \\
\rho_{d e t}=0 \quad \text { else }
\end{gathered}
$$

where $\rho_{d e t}$ is the detachment rate in $\mathrm{kg} \mathrm{m}^{-2} \mathrm{~s}^{-1}, \tau_{0}$ and $\tau_{0, c r}$ the mean bottom shear stress and its critical value in $\mathrm{N}$ $\mathrm{m}^{-2}, a$ the time constant in $s, B$ the fixed biomass in $\mathrm{kg} \mathrm{m}^{-2}$, and $\xi$ the exponent generally between 1 and 2.5 . We fixed $\xi=\frac{3}{2}$ as in most sediment erosion models [15]. The critical value of shear stress is assumed to be equal to the initial value of $\tau_{0}$ before the flush. The algae growth is neglected in this model, since we consider only short time periods for the flush simulation.

The detached part is transferred into the water column. This drift algae compartment is transported to the downstream end, which is simulated by the advection-dispersion equation based on mass conservation and Fick's law:

$$
\frac{\partial A C}{\partial t}+\frac{\partial Q C}{\partial x}=\frac{\partial}{\partial x}\left(D A \frac{\partial C}{\partial x}\right)+\rho_{D e t} P
$$

with $A$ the wetted area $\left(\mathrm{m}^{2}\right), Q$ the mean discharge $\left(\mathrm{m}^{3} \mathrm{~s}^{-1}\right), C$ the drift algae concentration $\left(\mathrm{kg} \mathrm{m}^{-1}\right), D$ the diffusion-dispersion coefficient $\left(\mathrm{m}^{2} \mathrm{~s}^{-1}\right)$ given by Fischer's formula, and $P$ the wetted perimeter (m). Solving this equation requires initial and boundary conditions. One boundary condition is given by upstream concentrations, while a second one is obtained by assuming no diffusion at the downstream end. The computation uses a splitting method, with Holly Preissmann numerical scheme for the convective part and Crank-Nicholson scheme for the diffusion. As the drift algae concentration is difficult to monitor continuously, the turbidity is used as an indirect indicator of the algae concentration [3]. Based on experimental results, the relation between the algae concentration and the turbidity is assumed to be linear during a flush.

\section{B. Linear model}

1) Hydraulic transfer: The simplified hydraulic model is based on the approach developed by Munier et al. [10]. The considered reach is supposed prismatic and homogeneous of length $X$ meters. The 1D Saint Venant equations (Eqs. 1 and 2) are linearized around a reference steady state regime $\left(Q(x, t)=Q_{r e f}(x)+q(x, t)\right)$ and re-written in the Laplace domain in order to identify the transfer function $T F(s)$ that links the upstream discharge to the downstream discharge:

$$
\widehat{q}(X, s)=T F(s) \widehat{q}_{0}(s)
$$

where $\widehat{q}_{0}=\widehat{q}(0, s)$ is the Laplace transform of the upstream discharge $q(0, t), \widehat{q}(X, s)$ is the Laplace transform of the downstream discharge $q(X, t)$, and $s$ is the complex Laplace variable. 
We choose an approximate first-order-with-delay using the moment matching method for the transfer function $T F(s)$ :

$$
\widehat{q}(X, s)=\widehat{q_{X}}(s)=\frac{e^{-\tau s}}{1+K s} \widehat{q}_{0}(s)
$$

where $\tau$ is the delay and $K$ the time constant. These two model parameters may be calculated from the canal characteristics [10] or may be calibrated using field measurements. This transfer function corresponds in the time domain to the following ordinary differential equation:

$$
\frac{d q(X, t)}{d t}=\frac{1}{K}\left(q_{0}(t-\tau)+q(X, t)\right)
$$

2) Detachment: The detachment is modeled here as a lumped process. Considering the biomass uniformly distributed, the discharge acting on the algae mat is supposed to be an intermediary discharge, located in the middle of the canal pool. The hydraulic transfer function is used to compute this discharge $q_{I}=q(x=X / 2)$, which is given by:

$$
\widehat{q_{I}}(s)=\frac{e^{-\tau^{\prime} s}}{1+K^{\prime} s} \widehat{q_{0}}(s)
$$

with $\tau^{\prime}=\frac{1}{2} \tau-\sqrt{\frac{1}{2}} K$ and $K^{\prime}=\sqrt{\frac{1}{2}} K$ according to [10] .

The intermediate discharge is used as an input to model the detachment considering that the detachment is due to an increase of the discharge. Then, the detached biomass is assumed to be linked to the discharge variation by a firstorder, with a derivative term. This means that the detachment is a function of the discharge variation. To avoid non physical results, only the positive values of the derivative of the discharge are considered as having an effect on the algae. This transfer function may also be derived from Eqs. 3 and 4 by linearization of the biomass $B$ and of the shear stress. Finally, a delay is added in order to take account of the transfer of the detached material to the downstream end. A gain accounts for the conversion between algae concentration and turbidity. The detachment transfer function $D F(s)$, that gives the turbidity response to the intermediate discharge $q_{I}$, is written as follows:

$$
D F(s)=\frac{\beta s e^{-\gamma s}}{1+\alpha s}
$$

The turbidity due to biomass detachment into the canal is finally given by:

$$
T_{b, d}(s)=D F(s) \widehat{q}_{I}(s)
$$

The upstream turbidity is also transferred along the reach as a solute using the hydraulic transfer function which gives:

$$
T_{b}(s)=T_{b, d}(s)+T F(s) \widehat{T}_{b, u}(s)
$$

where $T_{b, u}$ is the upstream turbidity. All the steps are summed up in Fig. 1.

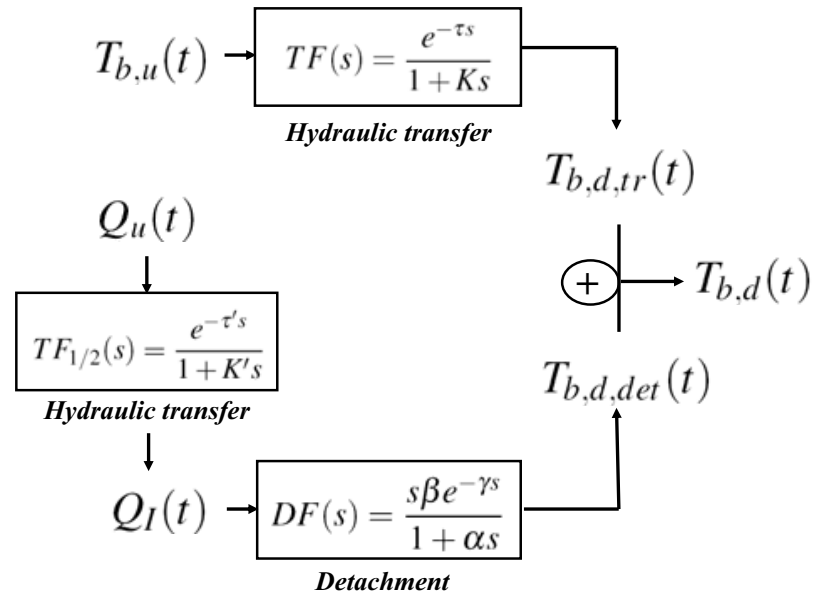

Fig. 1. Sketch of the model structure. $T_{b, u}(t)$ the upstream turbidity and $O_{u}(t)$ the upstream discharge are the input of the model. Hydraulic transfer parameters are used to compute the transport of downstream turbidity $\left(T_{b, d, t r}(t)\right)$ and the intermediate discharge $Q_{I}(t) . Q_{I}(t)$ is used to compute the downstream turbidity due to detachment $T_{b, d, d e t}(t) . T_{b, d, t r}(t)$ and $T_{b, d, d e t}(t)$ are added to compute $T_{b, d}(t)$ the downstream turbidity, the output variable.

\section{Application on the CANAl De Provence}

\section{A. Presentation of the case study}

Flushes are performed and monitored on a branch of the Canal de Provence called the Branch of Marseilles North $(\mathrm{BMN})$. The $\mathrm{BMN}$ is $32 \mathrm{~km}$ long and has a maximal discharge capacity of $3.5 \mathrm{~m}^{3} \mathrm{~s}^{-1}$. Water is supplied by the Bimont dam at the BMN head, $50 \%$ of the inflow water is withdrawn along the $\mathrm{BMN}$, and $50 \%$ is transported until the downstream end where it is stored into the Vallon Dol tank. Thanks to these pools, water is always available to perform a flush and no water is lost. The basis mean discharge is generally between 1 and $1.5 \mathrm{~m}^{3} \mathrm{~s}^{-1}$. To perform a flush this basis discharge is increased by $1 \mathrm{~m}^{3} \mathrm{~s}^{-1}$ during 6 hours. The hydraulic conditions (discharges and water levels) are measured at several stations along the canal. Some of these stations are also equipped with quality sensors for temperature and turbidity monitoring (accuracy of $\mathbf{X}$ NTU). These data are used to calibrate the model. The BMN provides $30 \%$ of the water requirements of the city of Marseille, consequently the water quality is a strong constraint for the manager. Especially, the water drinking plants are equipped with filtering systems adapted to the very low usual turbidity level of the Verdon River (which feeds the Canal de Provence). These systems are thus very sensitive to the level of turbidity. The manager fixes the maximal acceptable turbidity to 20 NTU (Nephelometric Turbidity Units). The simplified model is applied to the downstream reach located between two monitoring stations, which is about $10 \mathrm{~km}$ long.

\section{B. Identification of the hydraulic transfer parameters}

Firstly, we calibrate the hydraulic transfer function on measurements at the end of the reach $(x=X)$ which requires the identification of only two parameters, $K$ and $\tau$. The 
TABLE I

MOdel PARAMETERS CALIBRATION ON THE BMN DATA

\begin{tabular}{|c||c|}
\hline Parameter & values \\
\hline$K$ & $0.67 \mathrm{~h}$ \\
$\tau$ & $1.23 \mathrm{~h}$ \\
$\alpha$ & $5.12 \mathrm{~h}$ \\
$\gamma$ & $1.48 \mathrm{~h}$ \\
$\beta$ & 282.25 \\
\hline
\end{tabular}

parameters are calibrated to fit the simulated discharge at the downstream station to the measurements by minimizing the sum of the square errors. Optimized parameters values are given in Table I. The simulated discharge at the downstream zone is compared with the measurements in Fig. 2. The output of the first-order-with-delay model represents very well the downstream discharge.
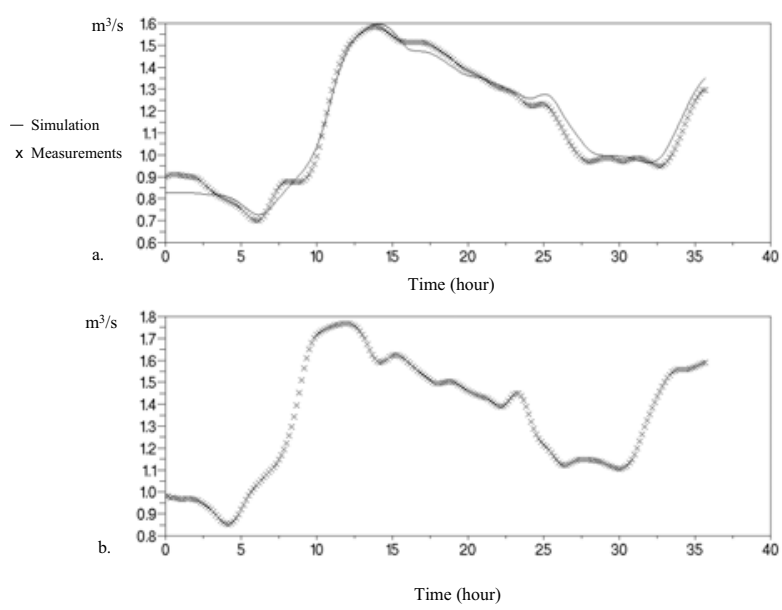

Fig. 2. Simulated and measured (experimental results) discharges at the downstream node (a.) and measured (experimental results) discharge at the upstream node of the channel(b.)

\section{Detachment and transport of algae}

The detachment function requires the calibration of three parameters: $\alpha, \beta$, and $\gamma$. They are calibrated by minimizing the sum of square errors between simulated and registered turbidity at the downstream station presented in Fig. 3. Parameters values are given in Table I. Calibrating hydraulic and then detachment parameters, the turbidity at the end of the reach is also correctly simulated for different flushes.

The simplified model has also been tested on other canal pools, leading to very good results. This model is now used in the next section to design open-loop controllers, in order to efficiently flush the algae.

\section{APPLiCATION TO FLUSH DESIGN: OPEN-LOOP CONTROLLER}

\section{A. Flush design under constraints: principles}

The flush is performed by increasing the head discharge during several hours. This operation is characterized by three criteria (see Fig. 4):
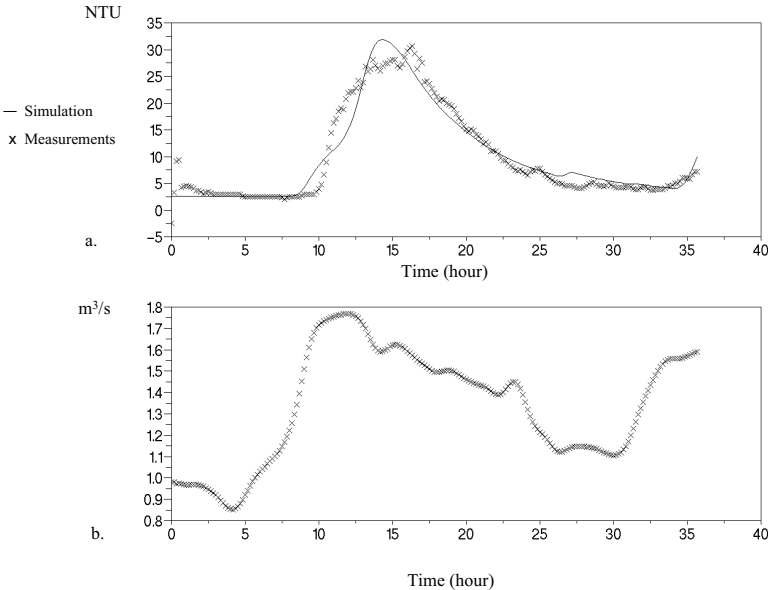

Fig. 3. Simulated and measured (experimental results) turbidity at the downstream node (a.) and measured (experimental results) discharge at the upstream node of the channel(b.)

- the amplitude of the discharge increase, denoted $\Delta Q$,

- the time to reach the high discharge value, denoted $\Delta t_{1}$, and

- the duration of discharge increase, denoted $\Delta t_{2}$.

The objective is to maximize the algae detachment using as low water as possible, and without overcoming the maximum of $20 \mathrm{NTU}\left(T_{b} M A X\right)$. The three criteria we use for the flush efficiency assessments are thus: the volume of water release, denoted $V_{w}$, the maximal value of turbidity reached during the flush $T_{b M}$, and the integrate of the turbidity during the flush $I_{d e t}$ which is used as an indicator of the volume of detached biomass. The higher will be the values of $\Delta Q$, $\Delta t_{1}$ and $\Delta t_{2}$, the higher will be the detachment but also the volume of water released and the risk of overcoming the maximum level of turbidity. Designing a flush therefore consists in defining the values of $\Delta Q, \Delta t_{1}$ and $\Delta t_{2}$ while fulfilling some constraints on the three criteria $V_{w}, T_{b M}$ and $I_{d e t}$.

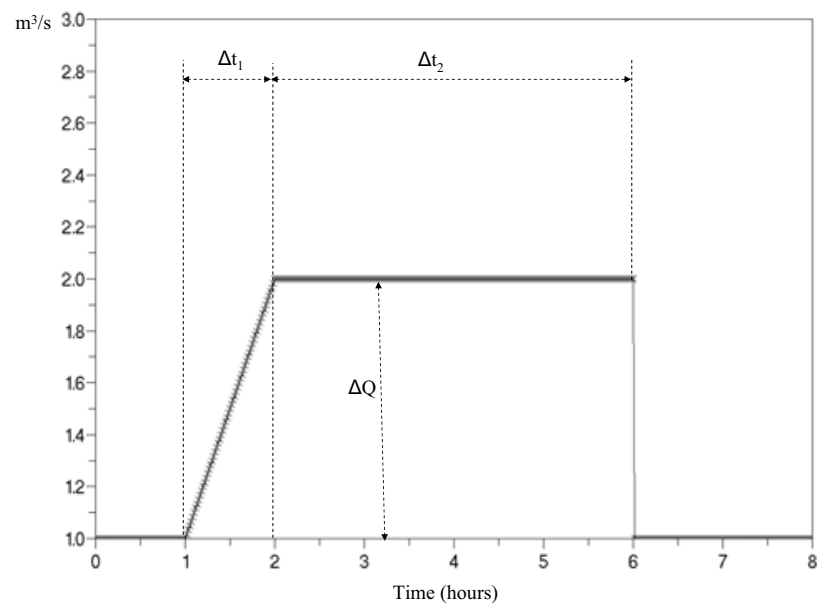

Fig. 4. The criteria which characterize the flush are the amplitude $(\Delta Q)$, the time to reach the high discharge value $\left(\Delta t_{1}\right)$, and the duration $\left(\Delta t_{2}\right)$. 


\section{B. Flush design optimization}

Using the simplified linear model, one may express analytically the downstream turbidity as a function of the upstream discharge, therefore as a function of the parameters of the flush. After tedious but straightforward computations, we get:

$$
\begin{aligned}
T_{b}\left(t-\tau^{\prime}-\gamma\right)= & 0 \text { if } t \leq \tau^{\prime}+\gamma \\
T_{b}\left(t-\tau^{\prime}-\gamma\right)= & \frac{\Delta Q \beta}{\Delta t_{1}\left(\alpha-K^{\prime}\right)}\left(\alpha\left(1-e^{-\frac{t}{\alpha}}\right)-K^{\prime}\left(1-e^{-\frac{t}{K^{\prime}}}\right)\right) \\
& \quad \text { if } \tau^{\prime}+\gamma<t \leq \tau^{\prime}+\gamma+\Delta t_{1} \\
T_{b}\left(t-\tau^{\prime}-\gamma\right)= & \frac{\Delta Q \beta}{\Delta t_{1}\left(\alpha-K^{\prime}\right)}\left(\alpha\left(1-e^{-\frac{t}{\alpha}}\right)-K^{\prime}\left(1-e^{-\frac{t}{K^{\prime}}}\right)\right. \\
& \left.-\left(\alpha\left(1-e^{-\frac{t-\Delta_{1}}{\alpha}}\right)-K^{\prime}\left(1-e^{-\frac{t-\Delta t_{1}}{K^{\prime}}}\right)\right)\right) \\
& \text { if } t>\tau^{\prime}+\gamma+\Delta t_{1}
\end{aligned}
$$

This expression provides analytical formula of the three criteria in function of the flush features which can be used to optimize the design of the flush. The maximum value of turbidity is reached for $t=t_{M}$ defined as:

$$
t_{M}=\frac{\alpha K^{\prime}}{\alpha-K^{\prime}} \log \left(\frac{K^{\prime}\left(e^{\frac{\Delta t_{1}}{K^{\prime}}}-1\right)}{\alpha\left(e^{\frac{\Delta t_{1}}{\alpha}}-1\right)}\right)
$$

The corresponding turbidity is expressed as:

$$
\begin{aligned}
T_{b, M}= & \frac{\Delta Q \beta}{\Delta t_{1}\left(\alpha-K^{\prime}\right)}\left(\alpha\left(1-e^{-\frac{t_{M}-\Delta t_{1}}{\alpha}}\right)-K^{\prime}\left(1-e^{-\frac{t_{M}-\Delta_{t}}{K^{\prime}}}\right)\right. \\
& \left.-\left(\alpha\left(1-e^{-\frac{t_{M}-\Delta_{1}}{\alpha}}\right)-K^{\prime}\left(1-e^{-\frac{t_{M}-\Delta_{1}}{K^{\prime}}}\right)\right)\right)
\end{aligned}
$$

The volume of water released for the flush is expressed as:

$$
V_{w}=\frac{1}{2} \Delta Q \Delta t_{1}+\Delta q \Delta t_{2}
$$

Finally the integral of turbidity which gives a indicator of the detached volume is given by:

$$
I_{d e t}=\Delta Q \beta\left(1+\frac{\alpha^{2} e^{\frac{-\Delta t_{2}}{\alpha}}\left(e^{\frac{-\Delta_{1}}{\alpha}}-1\right)-K^{\prime 2} e^{\frac{-\Delta_{2}}{K^{\prime}}}\left(e^{\frac{-\Delta_{1}}{K^{\prime}}}-1\right)}{\left(\alpha-K^{\prime}\right) \Delta t_{1}}\right)
$$

The simplified model therefore enables us to analytically express the output of a flush in terms of the design parameters. This is very useful for designing flushes.

\section{Design curves}

For the manager, the increase of discharge $\Delta Q$ is generally imposed by the canal capacity or the value of available discharge. In the studied reach, $\Delta Q$ is fixed to $1 \mathrm{~m}^{3} \mathrm{~s}^{-1}$. The expressions of the three design criteria are used to depict several curves that draw a better insight into the flush design. The maximal turbidity depends on the discharge increase and on the time to reach the maximum discharge (Eq. 5). The first design curve depicts the maximal turbidity as a function of $\Delta t_{1}$, for a given value of $\Delta Q$ (see Fig. 5). The value of $\Delta t_{1}$ can now be determined by the combination of the maximum acceptable level of turbidity (20 NTU) and the fixed value of $\Delta Q$. On the studied reach, with a $\Delta Q$ set to $1 \mathrm{~m}^{3} \mathrm{~s}^{-1}$, the value of $\Delta t_{1}$ needs to be at least 52 minutes to respect the turbidity maximum level. The volumes of detached biomass and of water are both function of the three criteria. Curves on Fig. 6 and 7 show the respective influence of the $\Delta Q$ and $\Delta t_{1}$ values on the relation between the detached volume and the flush duration or the volume of release water. According to Eqs. 6 and 7, the values of the volume criteria at the limits are:

$$
\begin{aligned}
\lim _{\Delta t_{2} \rightarrow 0} I_{\text {det }} & =\Delta Q \beta\left(1+\frac{\alpha^{2}\left(e^{\frac{-\Delta t_{1}}{\alpha}}-1\right)-K^{\prime 2}\left(e^{\frac{-\Delta t_{1}}{K^{\prime}}}-1\right)}{\left(\alpha-K^{\prime}\right) \Delta t_{1}}\right) \\
\lim _{\Delta t_{2} \rightarrow 0} V_{w} & =\frac{1}{2} \Delta Q \Delta t_{1} \\
\lim _{\Delta t_{2} \rightarrow \infty} I_{\text {det }} & =\Delta Q \beta
\end{aligned}
$$

These curves show that when $\Delta t_{2}$ tends to infinity, the volume of detached biomass reaches a maximum, which means that the flush is no longer efficient for long duration values. We fixed the objective of removing $80 \%$ of the maximum detached volume. For the previously fixed values of $\Delta Q$ and $\Delta t_{1}$, the optimal value of $\Delta t_{2}$ is thus $1 \mathrm{~h} 18$.

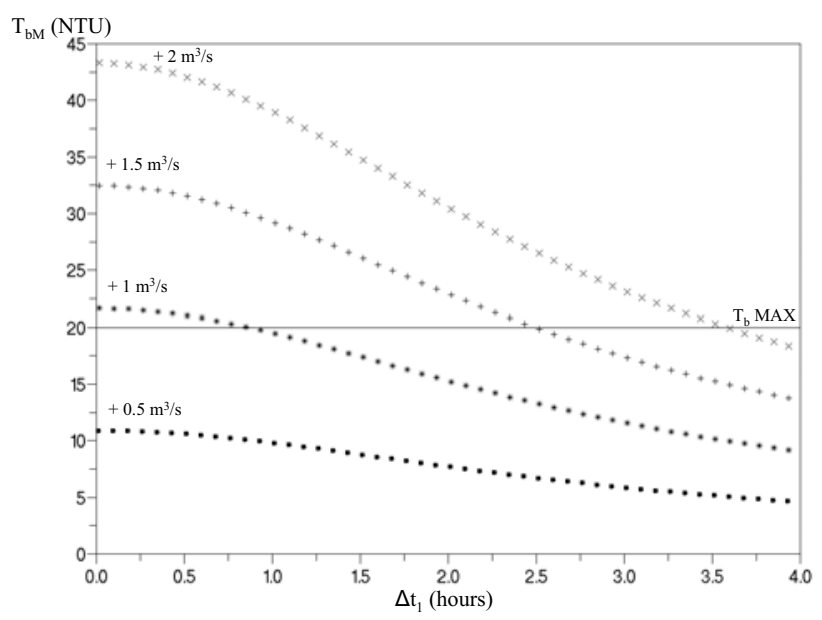

Fig. 5. Maximal turbidity curves in function of the values of $\Delta t_{1}$, each curve corresponds to a fixed value of $\Delta Q$.

The simplified model therefore enabled us to design a flush fulfilling the operational constraints of the system.

\section{Test of the designed flush}

The designed flush is simulated with the physical model presented above in Section II-A. Considering that the physical model has been validate for several flushes on the studied reach, this provides a simple test of the designed flush. The simulated downstream turbidity is depicted in Fig. 8. We observe that the maximum turbidity level is correctly estimated. The model is able to reproduce the amplitude and the duration of the turbidity peak at the downstream station.

\section{CONCLUSION}

We proposed in this article a simplified model for the detachment of filamentous algae in regulated open channels. The model is based on a semi-linear approximation, where only the positive discharge variations are taken into account 


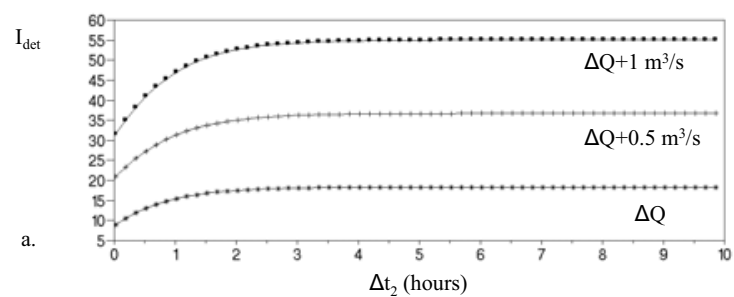

$I_{\text {det }}$

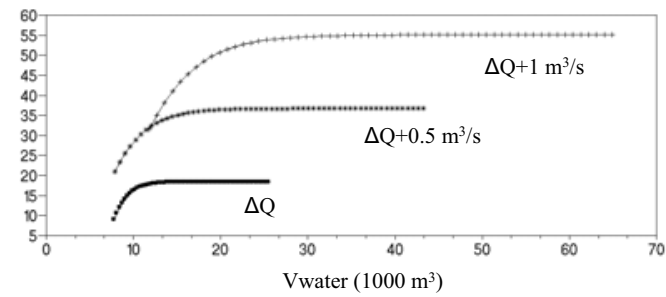

Fig. 6. Indicator of detached biomass volume in function of $\Delta t_{2}$ (a.) and of the added water volume for different values of $\Delta Q$ (b.)
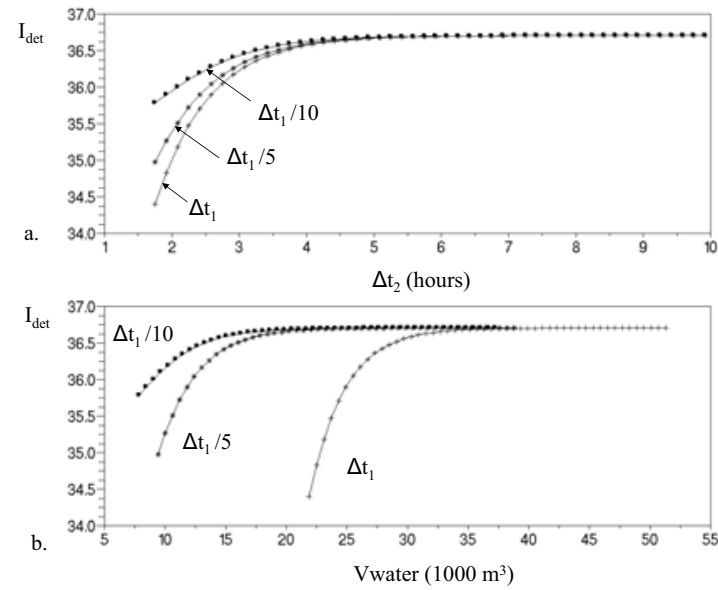

Fig. 7. Indicator of detached biomass volume in function of $\Delta t_{2}$ (a.) and of the added water volume for different values of $\Delta t_{1}$ (b.)
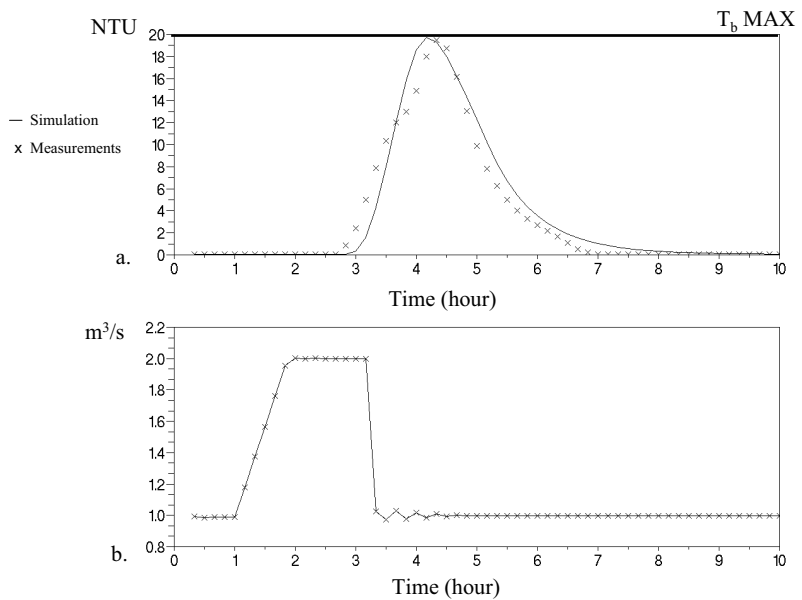

Fig. 8. Turbidity predicted with the open-loop, Turbidity computed using the SIC model, the maximal objective level is 20 NTU(a). Upstream discharge computed using the SIC model (b). for the detachment process. The resulting model is very simple and can be used to design efficient flushes that fulfill the manager's constraints. The model has been validated on real data. The flush designed with the model has been tested in simulation on a physical model solving the 1D SaintVenant equations coupled with a model for algae detachment and transport. These encouraging preliminary results will be tested in the field on a real site.

Finally, this open-loop control will be coupled with a feedback control in order to compensate for the inevitable discrepancies between the model and real data.

\section{ACKNOWLEDGMENTS}

The authors gratefully acknowledge the contribution of French National Research Agency through the project ALGEQUEAU and the Société du canal de Provence, who provided the data used for identification. This article is part of the Ph.D. thesis of Ophélie Fovet, under the supervision of Xavier Litrico and Gilles Belaud.

\section{REFERENCES}

[1] J-P. Baume, P-O. Malaterre,G. Belaud, B. Le Guennec, "SIC: a 1D Hydrodynamic Model for River and Irrigation Canal Modeling and Regulation”, Métodos Numéricos em Recursos Hidricos 7, Associacao Brasileira de Recursos Hidricos (ABRH), 2005, pp 1-81.

[2] A.J. Clemmens, E. Bautista, B.T. Wahlin, and R.J. Strand, Simulation of automatic canal control systems J. Irrig. Drain. Eng., vol. 131(4), 2005, pp 324-335.

[3] O. Fovet, G. Belaud, L. Lancar, X. Litrico, J-P. Baume, P-O. Malaterre, and O. Genthon, "Hydraulic Management of Filamentous Algae in Open-Channel Networks: Case Studies in Southern France", in 7th ISE \& 8th HIC, Chile, 2009.

[4] O. Fovet, G. Belaud, X. Litrico, S.Charpentier, C. Betrand, A. Dauta and C. Hugodot, Periphyton Modelling in Irrigation Canals, Eco. Modelling, vol. 221(8), 2010, pp 1153-1161.

[5] M. Gómez, J. Rodellar and J.A. Mantecón, Predicitive control method for decentralized operation of irrigation canals, Appl. Math. Modelling, vol. 26, 2002, pp 1039-1056.

[6] X. Litrico and V. Fromion, Frequency modeling of open-channel flow, J. Hydraul. Eng., vol. 130 (8), 2004, pp 806-815.

[7] X. Litrico and V. Fromion, Simplified modeling of irrigation canals for controller design, J. Irrig. Drain. Eng., vol. 130(5), 2004, pp 373-383.

[8] X. Litrico, P-O. Malaterre, J.-P. Baume, P.-Y. Vion and J. Ribot-Bruno, Automatic tuning of PI controllers for an irrigation canal pool, J. Irrig. Drain. Eng., vol. 133(1), 2007, pp 27-37.

[9] P-O. Malaterre, PILOTE: Linear quadratic optimal controller for irrigation canals, J. Irrig. Drain. Eng., vol. 124 (4), 1998, pp 187194.

[10] S. Munier, X. Litrico, G. Belaud, and P-O. Malaterre, Distributed approximation of open-channel flow routing accounting for backwater effects, Adv. Water Resour, vol. 31(12), 2008, pp 1590-1602.

[11] T. Rabbani, S. Munier, D. Dorchies, P.-O. Malaterre, A. Bayen and X. Litrico, Flatness-based control of open-channel flow in an irrigation canal using SCADA, Control Systems Magazine, Vol. 29(5), 2009, pp. 22-30.

[12] D.C. Rogers and J. Goussard, Canal control algorithms currently in use, J. Irrig. Drain. Eng., vol. 124(1), 1998, pp 11-15.

[13] J. Schuurmans, A.J. Clemmens, A. Hof and R. Brouwer, Modeling of irrigation and drainage canals for controller design, J. Irrig. Drain. Eng., vol. 125(6), 1999, pp 338-344.

[14] Robert G. Wetzel, Limnology, Saunders College Publishing, 1983.

[15] W. Wu, Computational River Dynamics, Taylor and Francis Group, London, UK, 2008.

[16] M. Xu, P.J Van Overlopp, N.C. Van De Giesen and G.S. Stelling, Realtime control of combined surface water quantity and quality: Polder flushing, Water Sc. and Tech., vol. 61(4), 2010, pp 869-878. 